\title{
Strategic Planning of Regional Development as Instrument of Ensuring Stability and Economic Security of a Territory
}

\author{
Elena Lobkova ${ }^{1, *}$,Konstantin Lobkov ${ }^{2}$, and Natalia Mehta ${ }^{3}$ \\ ${ }^{1}$ Siberian Federal University, Krasnoyarsk, Russia \\ ${ }^{2}$ Reshetnev Siberian State University of Science and Technology, Krasnoyarsk, Russia \\ ${ }^{3}$ Divine Mercy College, Perth, Australia
}

\begin{abstract}
Strategic planning of the region is an important and effective method of building a rational system of mechanisms for state management of regional development. The development of a regional strategy makes it possible to identify the reserves of the systemic development of territories, which contributes to the economic growth of the country. Within the framework of strategic planning for the development of the territory, the most acute problem is the forecasting of macroeconomic indicators on which the subsequent strategic plans and programs of the region are based. In this regard, the issues of forecasting indicators and assessing potential risks are highly relevant. The study is aimed to develop a tool for predicting the social-and-economic parameters of the regional system in order to build effective strategic plans for regional development within the framework of the concept of ensuring the sustainability and economic security of the territory. The authors propose an approach based on the delta-normal method for calculating a quantitative risk measure. The approach is adapted to solve the problem of probabilistic assessment of indicators of the state of the system and risks and allows to determine the ranges of changes in the predicted indicator of the gross regional product of the region, considering the probable increments of factor indicators. The results of applying the developed approach may be used as the basis for strategic planning of measures to manage sustainability, economic security and dynamics of the territory's development.
\end{abstract}

\section{Introduction}

Strategic planning and regional management is a process that includes: defining longterm goals of social-and-economic development; identification of constraints and problems causing deviations in the trajectory of the social-and-economic sphere; highlighting priority sectors and areas of economic development; formation of a program for the use of tools within the framework of the mechanism for managing regional processes and phenomena; development of a plan to enhance the efficiency of the management process

* Corresponding author: elenavalerin@yandex.ru 
and the functioning of the system of institutions that ensure the implementation of the adopted management decisions.

The strategizing process includes the stages of goal-setting, forecasting, planning, monitoring the social-and-economic development of the region and monitoring the implementation of strategies.

Within the framework of goal-setting, the region is considered as the middle link in the hierarchy of social-and-economic systems: the macroeconomic goals of regional development coincide with the goals of the national system; mesoeconomic goals of regional development aggregate the goals of micro-level entities (enterprises, business entities) in a sectoral context. The setting of goals in the strategic planning system of the region is based on the long-term prospects for the development of the territory, considering the resources available to it, the possibilities of activating the potential and overcoming probable threats [1-5].

Forecasting the strategic trajectory of the region is based on: analysis of the social-andeconomic situation in the region; study of the external environment of the region - patterns of regional, national and world level; considering the conditions for doing business and the interests of the main subjects of strategizing - authorities (state and local), entrepreneurs, industries and the public. The result of this stage is the development of forecast trends in the social-and-economic development of the territory.

Territorial development planning implies the choice of a strategy for the social-andeconomic development of the region, as well as the determination of the strategy planning horizon. The next stage is the monitoring of the current regional situation as the general state of the regional environment: the state of the natural-climatic, spatial, sociodemographic, economic, ecological, natural resource, socio-political, cultural-historical, national-ethnic potential of the territory within the administrative borders of the Russian Federation constituent entities and municipalities. An important component of many regional situations is intraregional proportions in the development of the social-andeconomic system.

The final stage of strategizing is control over the implementation of the strategy, supplemented by an analysis of missed opportunities, risks, threats and damage from their implementation. This is followed by the introduction of the necessary changes and adjustments to targets, tasks and activities [6].

The strategy of the social-and-economic development of the region is aimed at changing the social (strategy for the development of human resources, increasing employment, expanding employment opportunities, expanding the demographic and social potential, etc.), economic (strategy for increasing the life population quality, improving the structure of the region's economy, supporting and developing entrepreneurship and others) and territorial space (territorial planning, the system of interaction of territories, etc.) of the regional system. An effective territorial planning scheme requires the definition of functional zones, zones of the planned territorial distribution of capital construction objects, territories with special conditions of use, etc. The optimum territorial planning scheme is necessary for the most efficient use of the territory, its potential and resources, and balanced development.

The most important goals of regional strategizing are identifying the reserves of economic growth and competitiveness of the region, as well as attracting investments for the development of the territory. Herewith, the emphasis is on building an optimal production structure, stimulating specific priority and promising industries, overcoming development restrictions (threats and obstacles), as well as developing a system of measures for managing the territory in the forecast period.

The most acute problem is the formation of an integrated regional management system to ensure stable development in an unstable external environment. The solution to this 
problem lies in the plane of the mechanisms of regional management, based on a set of tools and methods for assessing the potential of the territory and its effective use.

The most important methodological problems of strategic planning of regional development are: the formation of the optimal structure of the regional economy and its individual elements; increasing the efficiency of the regional management instruments in the field of solving the problem of increasing the life population quality, developing entrepreneurship and competition, ensuring the rational use of the territory's potential; forecasting the main macroeconomic parameters, resource and capital flows; development of an integrated system for dynamic monitoring of regional processes, situations, problems and reforms. The presence of a significant number of authors' studies in the field of strategic planning of territories and their continued growth indicate the relevance of the problem of developing questions of the methodological nature of this area $[7,8]$.

\section{Research Methodology}

As one of the approaches to the procedure for forecasting social-and-economic indicators and the level of economic security of the region, the authors propose the use of assessment tools based on the theory of portfolio analysis [9].

In theory and practice, various methods have been developed for predicting the socialand-economic development of regions and countries [10-12]. The most frequently used and traditional methods of forecasting poorly consider the instability of the economic and political environment, the behavior of economic agents, the social situation, relying mainly on the pessimistic, basic and optimistic options for the development of the situation [13]. In addition, the methodological approaches differ in the way of describing the object and the environment in which it is located and developing, the ratio of the initial information and the method used, the temporal possibilities of the forecast and the probability of its execution, the goals of the procedure $[14,15]$.

To assess the dynamics of complex weakly formalized social-and-economic systems, the authors often use simulation models that allow to consider the impact of a large number of factors of a stochastic nature in conditions of information uncertainty, to identify and probabilistically evaluate a significant number of alternatives, scenarios and strategies for the development of the territory [16-18].

The information support system for the process of forecasting the social-and-economic development of the territory includes: monitoring the social-and-economic parameters of the system; development of a mechanism for selecting measures to prevent risks and minimize them; an information and analytical system for supporting the process of making managerial decisions, including the implementation of multivariate calculations of the scenario type of social-and-economic development of regions and an assessment of the consequences of decision-making [19, 20].

The construction of a system for assessing the consequences of decision-making for public authorities is complicated by the capacity and scale of the information flow in the space of the entire country and its territorial units; high probability of occurrence of difficultly predictable events; the complexity and complexity of social-and-economic problems; high probability of impact of phenomena, processes and trends that reduce the efficiency of decisions; the need to consider the conjugate action of a number of factors of different nature and orientation [21].

The process of identification and analysis of risks within the framework of forecasting the development of the social-and-economic system at the macro level is the basis of the risk assessment procedure for decision-making by governing bodies [22]. 
Assessment of the level of economic security of a territory requires the most accurate forecasts for the formation of effective measures of state regional policy, which necessitates the search for reliable methods of calculations and analysis. In an integrated approach, this makes it possible to solve the main tasks of social-and-economic policy: raising the standard of living of the population; ensuring a balanced development of the social sphere, economy and ecology; solving issues and problems of economic security and sustainability [23-26].

One of the approaches to assessing the predicted values of the level of economic security of the territorial system based on the analysis of threats is a method based on the idea of assessing the risks of financial assets. A quantitative measure of risk may be the probability of an event (threat realization) or the mathematical expectation of damage arising from the realization of hazards.

This approach includes a number of sequential procedures.

1) To calculate the security level of a region, the indices that make it up are presented in the form of functions of dependence on a certain set of social-and-economic risk factors. A requirement is established pursuant to which changes (relative or absolute increments $\Delta \rho$ ) of risk assessment indicators belong to the normal distribution:

$$
\Delta \rho \sim N(\delta, C) \text {, }
$$

where $\delta$ - vector-column of average increments of values of indicators-risk factors;

$\mathrm{C}$ - covariance matrix of increments in the values of risk factors.

The values of the level of economic security are the values of the dependence function that approximates the sensitivity of the territorial system to changes in the factors of socialand-economic risk. In this context, the issue of choosing risk factors is very acute and problematic, the combination of which, when evaluated, would give an acceptable result for the study and would not be redundant for making calculations, significantly complicating them.

The level of economic security of the region (S) is a function of dependence on variables - risk factors $\left(\rho_{\mathrm{i}}\right)$ :

$$
\mathrm{S}=\mathrm{f}\left(\rho_{\mathrm{i}}\right)
$$

2) The indicators of the sensitivity of the terms of the economic security of the region (S) to changes in risk factors are subjected to further assessment. Based on the sensitivity indicators, the variance of changes in the level of economic security of the region is calculated (in relative or absolute terms $\Delta S$ ) through the variance and covariance of the growth rates of risk factors.

Changes (relative or absolute increments) in the safety level in the vicinity of its current value may be decomposed by the Taylor formula:

$$
\Delta S=f\left(\Delta \rho_{i}\right) \approx \frac{\partial S}{\partial \rho_{1}} \Delta \rho_{1}+\frac{\partial S}{\partial \rho_{2}} \Delta \rho_{2}+\ldots+\frac{\partial S}{\partial \rho_{n}} \Delta \rho_{n}
$$

Then changes in the level of safety through relative changes in risk factors may be represented as:

$$
\Delta S \approx\left(\rho_{1} \frac{\partial S}{\partial \rho_{1}}\right) \frac{\Delta \rho_{1}}{\rho_{1}}+\left(\rho_{2} \frac{\partial S}{\partial \rho_{2}}\right) \frac{\Delta \rho_{2}}{\rho_{2}}+\ldots+\left(\rho_{n} \frac{\partial S}{\partial \rho_{n}}\right) \frac{\Delta \rho_{n}}{\rho_{n}},
$$

where $\rho_{i} \frac{\partial S}{\partial \rho_{i}}$ - indicators of the sensitivity of the level of economic security of the territory to changes in risk factors.

3) The sensitivity indicator may be presented as the product of the coefficient of change by the current value of the risk factor. Since the standard deviation is a homogeneous function, these coefficients will also relate the standard deviation of the safety level to the standard deviations of the relative increases in risk factors. The variance of changes in the security level may be estimated using the following formula:

$$
\sigma_{\Delta \mathrm{S}}^{2} \approx \mathrm{k}_{1}^{2} \sigma_{1}^{2}+\mathrm{k}_{2}^{2} \sigma_{2}^{2}+\ldots+\mathrm{k}_{\mathrm{n}}^{2} \sigma_{\mathrm{n}}^{2}+2 \mathrm{k}_{1} \mathrm{k}_{2} \sigma_{1} \sigma_{2} \mathrm{r}_{1.2}+\ldots+2 \mathrm{k}_{\mathrm{n}-1} \mathrm{k}_{\mathrm{n}} \sigma_{\mathrm{n}-1} \sigma_{\mathrm{n}} \mathrm{r}_{\mathrm{n}-1 . \mathrm{n}}=\mathrm{S}^{2} \sigma_{\Delta \mathrm{S} / \mathrm{S}}^{2}
$$


where $k_{i}$ - the sensitivity of changes in the level of safety in relation to small changes in the relative increments of risk factors, $i=1,2, \ldots, n$;

$\sigma_{i}$ - standard deviation of the relative gains of the $i$-th risk factor;

$r_{i j}$ - correlation coefficient between relative gains of $i$-th and $j$-th risk factors, $i=1,2, \ldots, n$, $j=1,2, \ldots, n$.

4) The absolute change in the level of security of the region $(\triangle S)$ may be represented as:

$$
\Delta S=K^{T} \delta-t_{1-\alpha} \sqrt{K^{T} C K}=S\left(Z^{T} \delta-t_{1-\alpha} \sqrt{Z^{T} C Z}\right)
$$

where $K$ - vector-column of sensitivity coefficients of absolute changes in the level of security of the region in relation to the relative increments of risk factors;

$Z$ - a column vector of the sensitivity coefficients of the relative increase in the level of safety in relation to the relative increases in risk factors;

$\mathrm{t}_{1-\alpha}$ - a coefficient corresponding to a certain confidence level (at a $95 \%$ confidence level, the coefficient is 1.645 , at a $97.5 \%$ level, the coefficient is 1.96 and at a $99 \%$ confidence level, the coefficient is 2.33 );

$C$ - covariance matrix of relative increases in the values of risk factors;

$S$ - the current level of economic security of the region.

The economic security indicator may also be presented as a set of its constituent indicators, each of which is a function of one social-and-economic risk factor and has the same sensitivity to changes in the relative increments of this risk factor as the initial set of indicators. If such a decomposition of the general level of economic security into its components is performed, then it is possible to calculate the magnitude of changes (increments) of each of the obtained one-factor indicators. When assessing the cumulative change in the level of economic security of a region, it is necessary to consider the presence of correlations between its components and their increments.

5) Calculation of the absolute change in the level of economic security $(\Delta S)$ of the region involves the calculation of the variance of changes in the level of security. The change in the safety level, consisting of $\mathrm{n}$ one-factor baselines $(X)$, may be represented as follows:

$$
\Delta S \approx \frac{d X_{1}}{d \rho_{1}} \Delta \rho_{1}+\frac{d X_{2}}{d \rho_{2}} \Delta \rho_{2}+\ldots+\frac{d X_{n}}{d \rho_{n}} \Delta \rho_{n}
$$

6) An assessment of the change in the level of economic security of a region may be expressed through the relative increments of risk factors and selected one-factor indicators of security assessment:

$$
\Delta \mathrm{S} \approx\left(\rho_{1} \frac{\mathrm{dX}_{1}}{\mathrm{~d} \rho_{1}}\right) \frac{\Delta \rho_{1}}{\rho_{1}}+\left(\rho_{2} \frac{\mathrm{dX}}{\mathrm{d} \rho_{2}}\right) \frac{\Delta \rho_{2}}{\rho_{2}}+\ldots+\left(\rho_{\mathrm{n}} \frac{\mathrm{dX}}{\mathrm{d} \rho_{\mathrm{n}}}\right) \frac{\Delta \rho_{\mathrm{n}}}{\rho_{\mathrm{n}}}
$$

$\Delta \mathrm{S}$

$$
\begin{gathered}
\approx X_{1}\left[\frac{d X_{1}}{d \rho_{1}} \frac{\rho_{1}}{X_{1}} \frac{\Delta \rho_{1}}{\rho_{1}}\right]+X_{2}\left[\frac{d X_{2}}{d \rho_{2}} \frac{\rho_{2}}{X_{2}} \frac{\Delta \rho_{2}}{\rho_{2}}\right]+\ldots+X_{n}\left[\frac{d X_{n}}{d \rho_{n}} \frac{\rho_{n}}{X_{n}} \frac{\Delta \rho_{n}}{\rho_{n}}\right]==X_{1} a_{1} \frac{\Delta \rho_{1}}{\rho_{1}}+X_{2} a_{2} \frac{\Delta \rho_{2}}{\rho_{2}} \\
+\ldots+X_{n} a_{n} \frac{\Delta \rho_{n}}{\rho_{n}}
\end{gathered}
$$

where $X_{i}$ - univariate safety assessment indicators;

$\rho_{i}$ and $\Delta \rho_{i}-$ risk indicators and their increments;

$a_{\mathrm{i}}-$ coefficients of elasticity of one-factor indicators of economic security in relation to risk.

7) Direct assessment of the dispersion of absolute changes in the level of economic security is possible by calculating the expected volatility and correlation coefficients of risk 
factors. The magnitude of the absolute change in the level of security of the region may be estimated in the following way:

$$
\Delta \mathrm{S}=\mathrm{M}^{\mathrm{T}} \delta-\mathrm{t}_{1-\alpha} \sqrt{\mathrm{M}^{\mathrm{T}} \mathrm{CM}}=\mathrm{X}^{\mathrm{T}} \delta-\mathrm{t}_{1-\alpha} \sqrt{\mathrm{X}^{\mathrm{T} C X}}
$$

where $M-$ a column vector of sensitivity coefficients of safety assessment indicators to changes in the relative increments of risk factors;

$X-$ a column vector of the current values of the safety assessment indicators;

$\delta$ - a column vector of average (expected) relative increments of indicators for assessing the security of a region;

$\mathrm{t}_{1-\alpha}$ - a coefficient corresponding to a certain confidence level (at a 95\% confidence level, the coefficient is 1.645 , at a $97.5 \%$ level, the coefficient is 1.96 and at a $99 \%$ confidence level, the coefficient is 2.33);

$C$ - a covariance matrix of changes in the relative increments of safety assessment indicators, the elements of which are variances and covariance of safety and risk assessment indicators.

The delta-normal method described in general terms for assessing the predicted values of economic security indicators may be presented in the form of the following algorithm.

1) Calculation of the relative growth rates of safety indicators (with the possible, if necessary, the use of logarithm to bring to the normal distribution law):

$$
\mathrm{T}_{\mathrm{p}}=\ln \frac{\mathrm{X}_{\mathrm{t}}}{\mathrm{X}_{\mathrm{t}-1}}
$$

where $X_{t}$ and $X_{t-1}$ - values of indicators of economic security in the current and previous periods.

2) Calculation of the mathematical expectation, standard deviation and variance of the predicted indicators.

3) Calculation of the quantiles of the normal distribution function (Gaussian function).

4) Calculation of the values of economic security indicators with a given probability $(95 \%, 97.5 \%$ or $99 \%)$ for the following forecasting time interval:

$$
\mathrm{T}_{\mathrm{p}}^{\mathrm{t}+1}=(\mathrm{Q}+1) \times \mathrm{T}_{\mathrm{p}}{ }^{\mathrm{t}}
$$

where $Q$ - the quantile value for the normal distribution of the safety assessment indicator; $\mathrm{T}_{\mathrm{p}}{ }^{\mathrm{t}}$ - the values of the relative growth rates of the safety indicator at the current time;

$\mathrm{T}_{\mathrm{p}}{ }^{\mathrm{t}+1}$ - the values of the relative growth rates of the safety assessment indicator at the next moment in time.

5) Calculation of the value of the safety assessment indicator for several forecast periods with a given probability:

$$
\mathrm{T}_{\mathrm{p}}^{\mathrm{t}+\mathrm{n}}=(1+\mathrm{Q} \times \sqrt{\mathrm{n}}) \times \mathrm{T}_{\mathrm{p}}^{\mathrm{t}}
$$

where $Q$ - the quantile value for the normal distribution of the safety assessment indicator; $\mathrm{T}_{\mathrm{p}}{ }^{\mathrm{t}}$ - the values of the relative growth rates of the safety assessment indicator at the current time;

$\mathrm{T}_{\mathrm{p}}^{\mathrm{t}+\mathrm{n}}-$ the values of the relative growth rates of the safety indicator at the next moment in time;

$n-$ number of prediction periods (prediction interval).

Changes (increments) of one-factor assessment indicators at a given level of significance for each of the components of economic security are calculated by the formula:

$$
\Delta \mathrm{X}=\mathrm{t}_{1-\alpha} \times \sigma_{\mathrm{xi}} \times \mathrm{X}_{\mathrm{i}}
$$

where $X_{i}$ - the value of the indicator (one-factor component) of the economic security of the region;

$\sigma_{x i}-$ component volatility (standard deviation of the indicator);

$t_{l-\alpha}-$ coefficient corresponding to a given confidence level. 
In this case:

$$
\sigma_{\mathrm{xi}}=\sqrt{\sum_{\mathrm{i}}^{\mathrm{n}} \sum_{\mathrm{j}}^{\mathrm{n}} \alpha_{\mathrm{i}} \alpha_{\mathrm{j}} \operatorname{cov}_{\mathrm{ij}}}
$$

$\operatorname{cov}_{\mathrm{ij}}$ - covariations of $i$-th and $j$-th factors influencing the safety indicator;

$\alpha_{i}, \alpha_{j}$ - coefficients of the linear relationship between the components of economic security and risk factors, estimated by the regression method by constructing linear one-factor models;

$n-$ the number of components of the economic security of the region.

\section{Findings}

Let us show the application of the proposed method for assessing the predicted values of the economic security of the region.

Indicators-components of the assessment of the economic security of the Krasnoyarsk Territory were selected: the index of industrial production (as a percentage of the previous year); the degree of depreciation of fixed assets (in percent); fixed capital investment indices (as a percentage of the previous year); the cost of fixed assets (RUR mln). Calculations were made on the basis of annual data on indicators for the period 2010-2019.

The obtained forecast values of the gross regional product of the region (ref. table) indicate that the value of its absolute growth will be in the range $(89,373.6 ; 120,570.56)$ and will provide an increase in GRP by $3.86-5.22 \%$. GRP values are predicted in the range $(2,399,039.4 ; 2,630,236.80)$ with a probability of $99 \%$.

Table 1. The results of forecasting the indicator of the gross regional product of the region.

\begin{tabular}{|l|c|c|}
\hline \multicolumn{1}{|c|}{ Forecast period } & $\begin{array}{c}\text { Maximum GRP value prediction } \\
\text { (RUR mln.) }\end{array}$ & $\begin{array}{c}\text { GRP change (RUR mln.) - } \\
\text { absolute growth }\end{array}$ \\
\hline First $(\mathrm{t}+1)$ & $2,420,796.12$ & $111,129.9$ \\
\hline Second $(\mathrm{t}+2)$ & $2,516,827.62$ & $96,031.5$ \\
\hline Third $(\mathrm{t}+3)$ & $2,622,148.82$ & $105,321.2$ \\
\hline
\end{tabular}

Calculations of the maximum probable value of the change in the GRP of the forecast periods with a probability of $99 \%$ showed that in the first forecast period the quantitative assessment of the risk of deviation of the product indicator from its expected level is 111,129.9 RUR mln, in the second - 96,031.5 RUR mln, in the third - 105,321.2 RUR mln. (ref. table).

The application of the proposed methodology for predicting indicators of economic security and social-and-economic development of the territory is necessary for the development of corrective and supporting measures of state authorities, for making effective decisions in the field of economic and social policy.

Based on the study results, the authors formulated the conclusion that forecasting indicators of the economic security of a territory with the identification of significant factors based on the delta-normal method of assessing indicators allows to consider the risk of the impact of each of these factors on the predicted value of the feature under consideration. The presented example of forecasting the indicators of the Krasnoyarsk Territory demonstrates the use of the method for assessing the gross regional product based on the influence of factors reflecting the industrial production of the region, the cost and condition of fixed assets, investments in fixed assets of the territory. Standardized coefficients linking the estimated product indicator and factors revealed the greatest exposure of GRP to the influence of fixed assets indicators (risk indicator is the degree of depreciation of fixed assets; the cost of fixed assets at full book value). 


\section{Discussion}

The process of developing and implementing government decisions traditionally includes a system of goals that contribute to the achievement of a single general goal of the entire public administration system, and a set of risk factors (a system of risks), the assessment of which is largely hampered by a lack of information and limitations on the methods and tools used to identify these factors. The whole decision-making process, thus, is consistently complicated, requiring the authorities to involve other subjects of the socialand-economic system interested in the success of the management process.

The proposed method measures the sensitivity of the indicator of the state of the territorial system to risk only by changing the value of the factor. The indicator is calculated in proportion to the delta value (change in the indicator), while the sensitivity of the indicator to other risk factors also plays an important role.

Considering the risk of individual events (difficult to predict and control) that may lead to abnormal deviations from the predicted values and do not occur often enough to be presented in the latest historical data (on the basis of which correlations and volatilities of indicators are estimated) is possible by applying stress testing, which is a kind of scenario analysis.

\section{Conclusion}

The reaction of government bodies to the results of forecasting indicators of the state and development of a controlled system should consist in the processes of adapting decisionmaking structures, adjusting plans, targets and indicators of programs, the timing of their implementation, funding amounts, and specific activities.

The most problematic aspect of regional strategizing is the identification and assessment of social-and-economic risks due to their probabilistic nature and the complexity of forecasting, the possibility of exposure to unappreciated threats and the joint influence of a set of risk factors.

The natural, man-made, social, political and global factors may be difficult to control sources of the destructive impact of negative factors (risks) in the field of security of the social-and-economic system of the region. It is they that largely determine the complexity of predicting the dynamics of indicators of system development, which in turn makes it difficult to build an adequate forecast and strategy for ensuring the economic stability and security of the territory.

The study was performed with the financial support of the Russian Foundation for Basic Research, the Government of the Krasnoyarsk Territory, the Krasnoyarsk Regional Science Foundation in the framework of the scientific project: "Methodological, financial and institutional support for the development of a strategy for economic security of Yenisei Siberia in the context of digital transformation of the economy at the present stage", No. 20-410-242912.

\section{References}

1. D. S. Khairullov, U. A. Saipullaev, Mediterranean J. of Social Sciences 15 (12), 177 (2014). doi: 10.5901/mjss.2014.v5n12p177

2. S. I. Kolesnikov, L. M. Dolzhenko. Methodology for Assessing the Level of the Territory's Economic Security. Mathematical Analysis With Applications. Springer International Publishing, 318 (2020) doi: 10.1007/978-3-030-42176-2_35

3. Y. Nam, Y. Lee, S. McMahon, M. Sherraden, J. of Consumer Affairs 50 (3), 611 (2015) doi:10.1111/joca.12078 
4. A. A. Skomoroshchenko, E. S. Mishenkova, A. V. Kolesnik, Modern problems of science and education 1(2), 101 (2020). doi:10.17513/vaael.989

5. Q. Wang, C. Yang, L. Tian. Safety risk assessment of heritage buildings in metro construction based on SPA theory: a case study in Zhengzhou, China. Herit Sci. 8, 100 (2020) doi: 10.1186/s40494-020-00439-3

6. Yu. N. Zubarev, Economics: yesterday, today, tomorrow 8(11A), 41 (2018)

7. J. Stankevičienè, A. Miečinskienè, T. Sviderskè, Entrepreneurial Business and Economics Review 3, 21 (2013)

8. V. A. Tsvetkov, M. Dudin, N. V. Lyasnikov, Economy of Region 15(1), 1 (2019). doi: 10.17059/2019-1-1

9. A.A. Ufimtsev, Bulletin of the Chelyabinsk State University 8 (262), 137 (2012)

10. A. M. Alexandrov, Bulletin of the Chelyabinsk State University 4, 174 (2006)

11. L. A. Ginis, Bulletin of the Southern Federal University. Engineering Science 3, 231 (2009)

12. E.S. Pridvorova, Scientific Bulletin of Belgorod State University 1-1 (144), 5 (2013)

13. S.V. Mukin, Bulletin of Tomsk State University 7, 75 (2009)

14. E. A. Balashova, V. I. Chernetsov, Bulletin of the Saratov State Technical University 1, 139 (2009)

15. V. V. Krivorotov, A. V. Kalina, I. S. Belik, UrFU Bulletin 18(6), 892 (2019). doi: 10.15826 / vestnik.2019.18.6.043

16. A. Nazarov, Society. Politics. Economy. Right. 12 (2017). doi: 10.24158/pep.2017.12.21

17. V. A. Romashchenko, Kant 2 (11), 56 (2014)

18. Q. Zhou, J. Luo, The study on evaluation method of urban network security in the big data era. Intelligent Automation \& Soft Computing, 1 (2017) doi: 10.1080/10798587.2016.1267444

19. A.B. Arkhipov, Problems of Economics 9, 236 (2015)

20. V. I. Novoseltsev, A. V. Dushkin, V. I. Sumin, Modeling of security systems. Voronezh. 197 p. (2019)

21. A. V. Chaplinsky, S. M. Plaksin, Issues of state and municipal management 2, 7 (2016)

22. N.S. Maslova, I.V. Kuznetsova, Risk Assessment as an Institution for Managing State Needs, 482 (Moscow: HSE Publishing House, 2012)

23. A. A. Ivanova, A. M. Tufetulov, R. I. Gazizullin, Modern Economy Success 6, 16 (2020)

24. S.I. Kolesnikov, Problems of economic security: theory and practice, Yekaterinburg: UGLTU, 167 p. (2019)

25. N.V. Moiseev. Economic security criteria. Economic Issues 12, 35 (2015)

26. S. I. Morozov, O. V. Asmus, O. V. Zhigalova, Economic Relations 9(3), 1683 (2019) 